\title{
List B Free Recall (CVLT-C)
}

National Cancer Institute

\section{Source}

National Cancer Institute. List B Free Recall (CVLT-C). NCI Thesaurus. Code C120395.

The second part of the California Verbal Learning Test for Children. A second list, List B, is presented, and the child is asked to recall as many words from this list as he or she can. 